\title{
Abnormal lipid peroxidation in patients with sleep apnoea
}

\author{
A. Barceló ${ }^{\#}$, C. Miralles ${ }^{+}$, F. Barbé*, M. Vila ${ }^{\#}$, S. Pons*, A.G.N. Agustí*
}

\begin{abstract}
Abnormal lipid peroxidation in patients with sleep apnoea. A. Barceló, C. Miralles, F. Barbé, M. Vila, S. Pons, A.G.N. Agustí. (C) ERS Journals Ltd 2000.

ABSTRACT: The prevalence of cardiovascular diseases is increased in patients with the obstructive sleep apnoea syndrome (OSAS). The fall and rise of arterial oxygenation that follows each apnoea may increase lipid peroxidation and contributes to explaining this association. In the present study, the authors determined lipid peroxidation in patients with OSAS and the effect of treatment with continuous positive airway pressure (CPAP).

Fourteen male patients with severe OSAS $\left(59 \pm 5\right.$ apnoea $\left.^{-1} h^{-1}\right)( \pm$ SEM) and 13 healthy nonsmoking, male volunteers of similar age were studied. Patients were studied at diagnosis and after treatment with CPAP for more than $1 \mathrm{yr}\left(>4 \mathrm{~h} \cdot \mathrm{night}^{-1}\right)$. A venous blood sample was obtained early in the morning after fasting all night. In patients with OSAS, a sample before and during sleep was also obtained. Low density lipoprotein (LDL) particles were isolated by sequential ultracentrifugation. Their level of oxidation was determined by the thiobarbituric acid assay (TBARs), and their susceptibility to oxidation by the lag phase measurement.

Patients with OSAS showed higher TBARs $(28.1 \pm 2.8$ versus $20.0 \pm 1.8 \mathrm{nmol} \cdot \mathrm{malon}-$ dialdehyde $\left.\cdot \mathrm{mgLDL}_{\text {protein }}{ }^{-1}, \mathrm{p}=\mathbf{0 . 0 2}\right)$ and shorter lag phase values $(\mathbf{8 3 . 8} \pm 3.4$ versus 99.7 $\pm 3.4 \mathrm{~min}, \mathrm{p}=\mathbf{0 . 0 0 5}$ ) than controls. These differences were not due to the smoking status of the patient. Likewise, these values did not change significantly throughout the night yet, the lag phase value was significantly improved by treatment with CPAP (124.9 \pm 8.5 min; $p<0.001)$.

These results indicate that obstructive sleep apnoea syndrome is associated with abnormal lipid peroxidation and that this is improved by chronic use of Continuous positive airway pressure. These results can contribute towards explaining the high prevalence of cardiovascular diseases seen in Obstructive sleep apnoea syndrome. Eur Respir J 2000; 16: 644-647.
\end{abstract}

Serveis de ${ }^{\#}$ Anailisi Cliniques and *Pneumologia and ${ }^{+}$Unidad de Apoyo a la Investigación, Hospital Universitari Son Dureta, Palma de Mallorca, Spain.

Correspondence: A.G.N. Agustí

Servei Pneumologia

Hospital Universitari

Son Dureta

Palma de Andrea Doria 55

07014 Palma Mallorca

Spain

Fax: 34971175228

Keywords: Atherosclerosis

cardiovascular diseases

cholesterol

hypoxia-reoxygenation

lipids

oxidative stress

Received: June 281999

Accepted after revision April 112000

This study was supported in part, by Fondo Investigación Sanitaria 96/1718, Sociedad Española de Neumologia y, Fundació Catalana de Pneumologia, Carburos Metlicos and Associació Balear per L'Estudi de les Malalties Respiratories.
The obstructive sleep apnoea syndrome (OSAS) is a frequent disease characterized by the occurrence of numerous episodes of absence of respiratory flow (apnoea) during sleep [1]. Each episode of apnoea is followed, in most patients, by a marked decrease in arterial oxygen saturation $\left(\mathrm{Sa}_{\mathrm{a}} \mathrm{O}_{2}\right)$ that is rapidly normalized when ventilation resumes (hypoxiareoxygenation) $(\mathrm{H} / \mathrm{R})$ [1]. Treatment with continuous positive airway pressure (CPAP) prevents the occurrence of apnoeas and the H/R episodes that follow them [2].

The prevalence of cardiovascular diseases is increased in OSAS [3-5]. The mechanisms underlying this association are unclear [6-8]. Because atherosclerosis is a hallmark of these vascular diseases, it is conceivable that OSAS may somehow contribute towards enhancing atherogenesis [6]. High plasma low density lipoprotein cholesterol (LDL) levels favour this process, especially if LDL particles have been previously oxidized $[9,10]$. The authors hypothesized that this may occur in OSAS due to the repetition of $\mathrm{H} / \mathrm{R}$ episodes throughout the night. Accordingly, a study that investigated: 1) the plasma levels of oxidized LDL (and its susceptibility to oxidation) in patients with untreated OSAS, as compared to healthy subjects was designed. Because the duration of apnoeas and the severity of the $\mathrm{H} / \mathrm{R}$ episodes increases throughout the night $[11,12]$, these same variables were analysed before, during and after sleep; and 2) the effects of long-term treatment $(>1 \mathrm{yr})$ with CPAP upon these indices of lipid peroxidation were also examined.

\section{Methods}

\section{Subjects and ethics}

Fourteen patients with OSAS and 13 healthy volunteers were studied. In patients, the diagnosis of OSAS was established by full polysomnography (Ultrasom Nicolett, Wis., USA). Each patient was studied twice: at diagnosis and after being effectively treated for at least $1 \mathrm{yr}$ with CPAP (REM Star; Respironics $(\mathbb{R}$, Murrysville, PA, USA). Five patients who did not use the device for a minimum of $4 \mathrm{~h} \cdot$ night $^{-1}$ (compliance was checked by the timer built up in the CPAP device) and two patients who refused to return to the laboratory were excluded from the second study. Thirteen healthy, nonsmoking, non-obese controls of a similar age, in whom OSAS was excluded clinically using criteria presented by KAPUNIAI et al. [13] were also studied. None of the patients had personal or familial history of cardiovascular disease or diabetes and none received 
medication. This investigation was approved by the Ethics Committee of the institution (the Hospital Universitari Son Dureta). All participants signed their consent after being fully informed of the nature and characteristics of the study.

\section{Protocol}

Patients with OSAS $(n=14)$ arrived at the institution at $\sim 9$ p.m., after fasting for at least $6 \mathrm{~h}$. A heparinized venous catheter (Abbocat $\mathrm{R}-\mathrm{T}$, Dublin, Ireland) was inserted into an antecubital vein to allow serial blood sampling through the night without disturbing sleep. Three different sample were obtained from the patients $(30 \mathrm{~mL}$ each, in ethylenediamine tetraacetric acid (EDTA) $\left.\left(1 \mathrm{~g} \cdot \mathrm{L}^{-1}\right)\right)$ : before going to sleep (sample A), after $5 \pm 1$ h of sleep (sample B) and $1 \mathrm{~h}$ after awakening (sample $\mathrm{C}$ ). This latter sample was followed by a fourth $(10 \mathrm{~mL}$, without anticoagulant) for general biochemical assessment (glucose, cholesterol, etc.) (sample D). Patients remained fasted during the study. In controls and patients studied after CPAP treatment, only two venous blood samples (samples C and D) were obtained at $\sim 9$ a.m., after fasting all night. Blood samples were immediately centrifuged during $15 \mathrm{~min}$ at 2500 revolution per minute (Jouan S.A., model CR4 22, SaintHerblain, France); the serum was analysed and the plasma frozen at $-80^{\circ} \mathrm{C}$ until analysis.

\section{Measurements}

The lipid profile of the serum samples was determined by routine laboratory techniques (Hitachi 717; Boehringer Mannheim; Germany). LDL (density $=1.019-1.063 \mathrm{~g} \cdot \mathrm{mL}^{-1}$ ) was isolated by sequential ultracentrifugation [14]. A Shepadhex G-25 column (PD - $10^{\mathrm{TM}}$; Pharmacia Biotech, Uppsala, Sweden) eluted with phosphate buffered saline (PBS) was used to eliminate salts from LDL samples. These were later filtered through $0.45 \mu \mathrm{m}$ filters (Millipore, Cedex, France). Protein content was determined using the Bradford method [15]. To assess the level of LDL oxidation the thiobarbituric acid assay (TBA) was used. In brief, samples were heated with TBA under acidic conditions, and the amount of chromogen formed was measured at $532 \mathrm{~nm}$ (Shimadzu, UV-160, Kyoto, Japan). The absorbance was expressed in malondialdehyde (MDA) equivalents $\mathrm{mg}^{-1}$ of LDL protein using a standard curve for MDA [16]. To ensure reproducibility of data, measurements were obtained in triplicate. The susceptibility of LDL to oxidation was investigated by the so-called lag phase, a standard technique in the field [17, 18]. The kinetics of conjugated denies formation was followed briefly by incubating LDL $\left(50 \mu \mathrm{g}\right.$ protein $\left.\cdot \mathrm{mL}^{-1}\right)$ at $30^{\circ} \mathrm{C}$ in PBS with $5 \mu \mathrm{mol} \cdot \mathrm{L}^{-1}$ of $\mathrm{Cu}^{++}[19,20]$. The generation of conjugated dienes during LDL oxidation was measured continuously by recording the absorbance at $234 \mathrm{~nm}$ every $5 \mathrm{~min}$ during a $4-5 \mathrm{~h}$ period. The intersection with the horizontal axis at a tangent to the slope of the propagation phase was used to calculate the lag phase (min) [19, 20].

\section{Statistical analysis}

Data is shown as the mean \pm SEM. The Student t-test (for paired or independent samples) and the one-way analysis of variance (ANOVA) were used to investigate the statistical significance of differences, as appropriate. Correlations between variables of interest were analysed using the Spearman rank test. A p-value lower than 0.05 was considered significant.

\section{Results}

All patients suffered from severe OSAS (mean apnoeahypopnoea index, $59 \pm 5 \mathrm{~h}^{-1}$ ), and showed frequent and profound episodes of arterial desaturation (mean nocturnal $\mathrm{Sa}_{2} \mathrm{O}_{2}, 92.1 \pm 1.0 \%$; mean lowest $\mathrm{Sa}_{2} \mathrm{O}_{2}$ during sleep $61.9 \pm 4.9 \%)$. Eight patients were smokers, 3 referred systemic hypertension and 2 had suffered (presented) an acute myocardial infarction in the past. On average, patients used CPAP for $5.5 \pm 0.7 \mathrm{~h} \cdot \mathrm{day}^{-1}$. Table 1 shows the main clinical and biological data of all the subjects studies. None of them changed significantly for the patients after treatment with CPAP.

Figure 1 shows the individual and mean thiobarbituric acid reactive substances TBARs (a) and lag phase values (b) determined in sample $\mathrm{C}$ in controls and in patients with OSAS. At diagnosis, patients with OSAS showed a higher TBARs concentration $(28.1 \pm 2.8$ versus $20.0 \pm 1.8$ $\mathrm{nmol} \mathrm{MDA} \cdot \mathrm{mg}^{-1}$ LDL protein, $\mathrm{p}=0.02$ ) and more susceptibility to LDL oxidation (shorter lag phase value) (83.8 \pm 3.4 versus $99.7 \pm 3.4 \mathrm{~min}, \mathrm{p}=0.005)$ than controls. This latter measurement, however, corresponds only to a subset of patients (fig. 1b), as only those in whom the available volume of LDL ensured adequate reproducibility of the measurement were included. TBARs concentration and lag phase values were similar in smoker and nonsmoker patients. In keeping with a recent study [21], no significant correlation between TBARs or lag phase values and: age, BMI, apnoea-hypopnoea index, mean or lowest $\mathrm{Sa}_{2} \mathrm{O}_{2}$ value at night was found. In contrast, the TBARS concentration was negatively related to the lag phase values (Rho $-0.72, p=0.03$ ). The abnormal TBARs and lag phase values determined in patients with

Table 1. - Mean \pm SEM values of several clinical and biochemical variables in patients with obstructive sleep apnoea syndrome (OSAS) (at diagnosis) and healthy subjects

\begin{tabular}{lcc}
\hline & $\begin{array}{c}\text { Patients with } \\
\text { OSAS }\end{array}$ & $\begin{array}{c}\text { Healthy } \\
\text { subjects }\end{array}$ \\
\hline Subjects $\mathrm{n}$ & 14 & 13 \\
Age yrs & $50 \pm 2^{*}$ & $44 \pm 2$ \\
BMI kg.m & $31.7 \pm 1.2^{* *}$ & $26.3 \pm 0.9$ \\
SBP $\mathrm{mmHg}$ & $139 \pm 4^{*}$ & $123 \pm 4$ \\
DBP mmHg & $82 \pm 3$ & $77 \pm 3$ \\
Total cholesterol $\mathrm{mmol} \cdot \mathrm{L}^{-1}$ & $5.5 \pm 0.2$ & $5.2 \pm 0.2$ \\
Triglycerides $\mathrm{mmol} \cdot \mathrm{L}^{-1}$ & $2.4 \pm 0.4^{*}$ & $1.3 \pm 0.1$ \\
LDL cholesterol $\mathrm{mmol} \cdot \mathrm{L}^{-1}$ & $3.59 \pm 0.32$ & $3.58 \pm 0.25$ \\
HDL cholesterol $\mathrm{mmol} \cdot \mathrm{L}^{-1}$ & $1.26 \pm 0.12$ & $1.31 \pm 0.12$ \\
\hline
\end{tabular}

BMI: body mass index; SBP: systolic blood pressure; DBP: diastolic blood pressure; LDL: low density lipoprotein; HDL: high density lipoprotein. *: $\mathrm{p}<0.05 ; * *$ : $<<0.005$. 

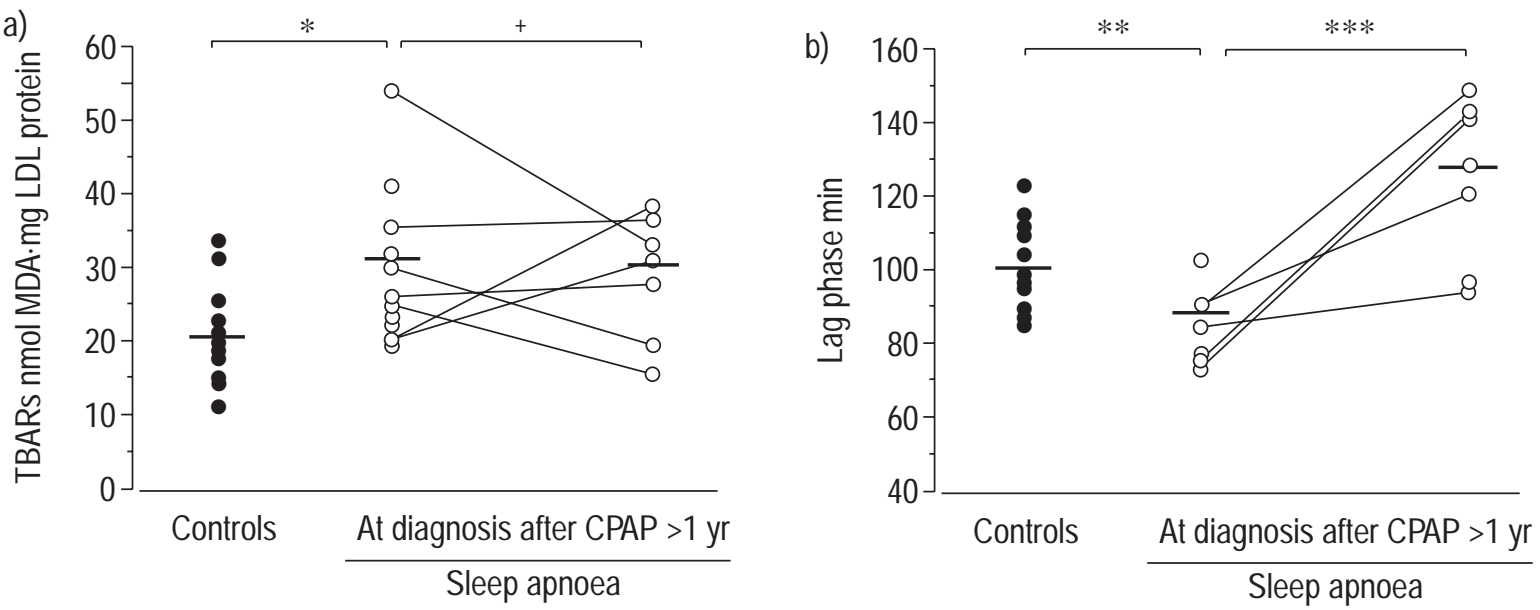

Fig. 1. - a) individual and mean values of thiobarbituric acid reactive substances and b) lag phase measured in healthy controls and in patients with obstructive sleep apnoea syndrome, before and after effective treatment with continuous positive airway pressure (CPAP) for at least 1 yr - : mean values; : healthy controls; $\bigcirc$ : obstructive sleep apnoea syndrome. $*: p=0.02 ;+: p=N s ; * *: p=0.005 ; * * *: p<0.001$.

OSAS did not change significantly through the night (table 2). Effective treatment with CPAP during more than one year did not modify the increased TBARs value $\left(27.9 \pm 3.2 \mathrm{nmol}\right.$ MDA. $\mathrm{mg}^{-1}$ LDL protein, $\left.\mathrm{p}=\mathrm{ns}\right)$ but markedly decreased the oxidation susceptibility of LDL (124.9 \pm 8.5 min; $\mathrm{p}<0.001$ ) (fig. 1).

\section{Discussion}

This study shows that abnormal lipid peroxidation occurs in patients with OSAS (fig. 1), and that it does not change appreciably through the night (table 2), and also chronic treatment with CPAP reduces the susceptibility of LDL to oxidation (fig. 1).

The mechanisms underlying the increased prevalence of cardiovascular diseases in OSAS $[4,5]$ are unknown $[3,6-$ 8]. To gain further insight into these mechanisms, the basal level of lipid peroxidation (TBARs content) and the oxidation susceptibility of isolated LDL particles (lag phase) in patients with untreated OSAS [18] was determined. It was found that these patients had increased TBARs levels and shorter lag phase values than healthy controls (fig. 1). These measurements were significantly related and highly reproducible through the night (table 2 ). Further, these results could not be explained by the smoking status of the patient. Collectively, these results indicate that increased lipid peroxidation occurs in OSAS. This may provide a mechanistic explanation for the high prevalence of cardiovascular diseases reported in these

Table 2. - Mean \pm SEM values of the thiobarbituric acid reactive substances (TBARs) and lag phase values determined in patients with obstructive sleep apnoea syndrome (OSAS) before, during and after sleep

\begin{tabular}{lccc}
\hline & $\begin{array}{c}\text { Before sleep } \\
(\sim 9 \mathrm{pm})\end{array}$ & $\begin{array}{c}\text { During sleep } \\
(\sim 5 \mathrm{am})\end{array}$ & $\begin{array}{c}\text { After sleep } \\
(\sim 9 \mathrm{am})\end{array}$ \\
\hline TBARs* & $31.1 \pm 3.4$ & $30.9 \pm 3.5$ & $28.1 \pm 2.8$ \\
Lag phase min & $89.9 \pm 4.6$ & $96.6 \pm 3.3$ & $83.9 \pm 3.4$ \\
\hline
\end{tabular}

*:nmol malondialdehyde.mg low density lipoprotein ${ }^{-1}$. No significant difference between test times (ANOVA). patients [3-5]. In the keeping with this hypothesis, a recent publication by SAARELAINEN et al. [21] demonstrated an increased concentration of autoantibodies against oxidized LDL in patients with OSAS. The results in this study, however, contradict a study by WALI et al. [22] that has failed to identify abnormal lipid peroxidation in OSAS. Methodological differences between the study conducted by WALI et al. [22] and the present study may probably explain this discrepancy. Finally, it was observed that chronic treatment with CPAP normalized the susceptibility of LDL particles to oxidation (fig. 1b), suggesting a potential beneficial effect of CPAP on excessive lipid peroxidation in OSAS. This was not the case in the study by WALI et al. [22]. However, these authors assessed the effects of CPAP only after 1 night of treatment [22], while the patients in this study were treated for more than $1 \mathrm{yr}$.

This study has some potential limitations that deserve comment: 1) the small number of subjects included in the study limits the conclusions. These will have to be confirmed in a larger series of patients with OSAS. Also, the potential effects of abnormal lipid peroxidation in important end organs of these subjects, such as the heart or the brain were not investigated. Future studies will also have to address this issue. 2) The controls were younger and had a lower BMI than patients with OSAS (table 1). However, differences were minor and probably of marginal biological significance. 3) In theory, obesity may have influenced the results independently of CPAP. The lack of TBARs changes after CPAP treatment may be explained by the absence of changes in BMI. However, the observation of less oxidation susceptibility of LDL after CPAP (fig. 1), in the absence of changes in BMI, suggests that obesity per se cannot explain the findings or at least not fully. 4) The fact that the effects of treatment with CPAP were not analysed in a randomized, controlled manner limit the strength of the conclusions. Finally, it is known that the oxidation of LDL is governed by three major factors: the amount of oxidizable substrate, the concentration of endogenous antioxidants, and the presence of oxidative stress $[10,23]$. Given that the concentration of antioxidants in the patients was not 
measured, its potential role in these patients remains speculative.

In summary, the results of this pilot study suggest that patients with obstructive sleep apnoea syndrome have abnormal lipid peroxidation and that chronic treatment with continuous positive airway pressure decreases the susceptibility of LDL to oxidation. These results may contribute towards explaining the relationship between obstructive sleep apnoea syndrome and cardiovascular disease. However, future studies will have to expand these results to a larger population, include measurements of antioxidants in plasma and investigate how this oxidative stress may impact important end organs of these patients.

Acknowledgements. The authors thank L.R. Mayorals for his help during the process of data collection, C. Santos for her technical help and the nursing personnel of the Servei de Pneumologia (Hospital Son Dureta, Palma Mallorca, Spain) for their collaboration during the study.

\section{References}

1. Douglas NJ, Polo O. Pathogenesis of sleep apnoea/ hypopnoea syndrome. Lancet 1994; 344: 653-655.

2. Sullivan CE, Berthon-Jones M, Issa FG, Eves L. Reversal of obstructive sleep apnoea by continuous positive airway pressure applied through the nares. Lancet 1981; 1: 862865.

3. Koskenvuo M, Kaprio J, Telakivi T, Partinen M, Heikkila $\mathrm{K}$, Sarna S. Snoring as a risk factor for ischaemic heart disease and stroke in men. BMJ 1987; 294: 16-19.

4. Hung J, Whitford EG, Parsons RW, Hillman DR. Association of sleep apnea with myocardial infarction in men. Lancet 1990; 336: 261-264.

5. Carlson JT, Hedner JA, Ejnell H, Peterson LE. High prevalence of hypertension in sleep apnea patients independent of obesity. Am J Respir Crit Care Med 1994; 150 . $72-77$.

6. Hedner JA, Wilcox I, Sullivan CE. Speculations on the interaction between vascular disease and obstructive sleep apnea. New York, Marcel Dekker, INC., 1994; pp. 823846.

7. Dean RT, Wilcox I. Possible Atherogenic Effects of Hipoxia During Obstructive Sleep Apnea. Sleep 1993; 16: S15-S22.

8. Fletcher EC. The relationship between systemic hypertension and obstructive sleep apnea: facts and theory. $\mathrm{Am}$ J Med 1995; 98: 118-128.

9. Steinberg D, Parthasarathy S, Carew TE, Witzum JL.
Modifications of Low-density lipoprotein that increase its atherogenicity. N Engl J Med. 1989; 320: 915-923.

10. Witzum JL. The oxidation hypothesis of atherosclerosis. Lancet 1994; 344: 793-795.

11. Charbonneau M, Marin JM, Olha A, Kimoff RJ, Levy RD, Cosio MG. Changes in obstructive sleep apnea characteristics through the night. Chest 1994; 106: 16951701.

12. Montserrat JM, Kosmas EN, Cosio MG, Kimoff RJ. Mechanism of apnea lengthening across the night in obstructive sleep apnea. Am J Respir Crit Care Med 1996; 154: 988-993.

13. Kapuniai L, Andrew D, Crowe LD, Pearce J. Identifying sleep from self- reports. Sleep 1988; 11: 430-436.

14. Havel RJ, Eder HE, Bracdon JH. The distribution and chemical composition of ultracentrifugally separated lipoproteins in human serum. J Clin Invest 1955; 34: 1345-1353.

15. Bradford M. A rapid and sensitive method for the quantitation of microgram quantities of protein utilizing the principle of protein-dye binding. Anals Biochem 1976; 72: 515-248.

16. Janero D. Malondialdehyde and thiobarbituric acidreactivity as diagnostic indices of lipid peroxidation and peroxidative tissue injury. Free Rad Biol Med 1990; 9: 515-540.

17. Regnström J, Nilsson J, Tornvall P, Landou C, Hamsten A. Susceptibility to low density lipoprotein oxidation and coronary atherosclerosis in man. Lancet 1992; 339: 11831186.

18. De Rijke YB, Vogelezang CJ, Van Berkel TJ, et al. Susceptibility of low-density lipoproteins to oxidation in coronary bypass patients. Lancet 1992; 340: 858859.

19. Kleinveld HA, Hak-Lemmers HLM, Stalenhoef AFH, Demacker PNM. Improved Measurement of LowDensity-Lipoprotein Susceptibility to Copper-Induced Oxidation: Application of a Short Procedure for Isolating Low-Density Lipoprotein. Clinical Chemistry 1992; 38: 2066-2072.

20. Esterbauer H, Striegl G, Puhl H, Rotheneder M. Continuous monitoring of in vitro oxidation of human low density lipoprotein. Free Rad Res Comms 1988; 6: 67-75.

21. Saarelainen S, Lehtimäki T, Jaakkola $\mathrm{O}$, et al. Autoantibodies against oxidised low-density lipoprotein in patients with obstructive sleep apnoea. Clin Chem Lab Med 1999; 37: 517-520.

22. Wali SO, Bahammam AS, Massaeli H, et al. Susceptibility of LDL to oxidative stress in Obstructive Sleep Apnea. Sleep 1998; 21: 290-296.

23. Fuller CJ, Jialal I. Effects of antioxidants and fatty acids on low density lipoprotein oxidation. Am J Clin Nutr 1994; 60: 1010-1013. 